\title{
Burial depth interval of the shale brittle-ductile transition zone and its implications in shale gas exploration and production
}

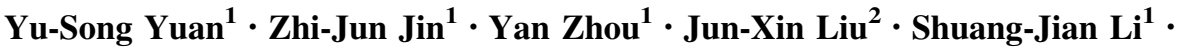 \\ Quan-You Liu'
}

Received: 2 January 2017 / Published online: 11 October 2017

(C) The Author(s) 2017. This article is an open access publication

\begin{abstract}
Brittleness and ductility of shale are closely related to shale gas exploration and production. How to predict brittleness and ductility of shale is one of the key issues in the study of shale gas preservation and hydraulic fracturing treatments. The magnitude of shale brittleness was often determined by brittle mineral content (for example, quartz and feldspars) in shale gas exploration. However, the shale brittleness is also controlled by burial depth. Shale brittle/ductile properties such as brittle, semibrittle and ductile can mutually transform with burial depth variation. We established a work flow of determining the burial depth interval of brittle-ductile transition zone for a given shale. Two boundaries were employed to divide the burial depth interval of shale brittle/ductile properties. One is the bottom boundary of the brittle zone (BZ), and the other is the top boundary of the ductile zone (DZ). The brittle-ductile transition zone (BDTZ) is between them. The bottom boundary of BZ was determined by the overconsolidation ratio (OCR) threshold value combined with pre-consolidation stress which the shale experienced over geological time. The top boundary of DZ was determined based on the critical confining pressure of brittle-ductile transition. The OCR threshold value and the critical confining pressure were obtained from uniaxial strain and
\end{abstract}

Yu-Song Yuan

yuanys.syky@sinopec.com

1 Sinopec Petroleum Exploration and Production Research Institute, 31 Xueyuan Road, Beijing 100083, China

2 Institute of Civil Engineering and Architecture, Southwest University of Science and Technology, Mianyang 621002, Sichuan, China

Edited by Jie Hao triaxial compression tests. The BZ, DZ and BDTZ of the Lower Silurian Longmaxi shale in some representative shale gas exploration wells in eastern Sichuan and western Hubei areas were determined according to the above work flow. The results show that the BZ varies with the maximum burial depth and the DZ varies with the density of the overlying rocks except for the critical confining pressure. Moreover, the BDTZ determined by the above work flow is probably the best burial depth interval for marine shale gas exploration and production in Southern China. Shale located in the BDTZ is semi-brittle and is not prone to be severely naturally fractured but likely to respond well to hydraulic fracturing. The depth interval of BDTZ determined by our work flow could be a valuable parameter of shale gas estimation in geology and engineering.

Keywords Shale $\cdot$ Brittleness $\cdot$ Fracture $\cdot$ Overconsolidation ratio $(\mathrm{OCR}) \cdot$ Confining pressure

\section{Introduction}

The increasing significance of shale gas plays has led to the need for deeper understanding of shale behavior (Dewhurst et al. 2015). In both exploration and production of shale gas, brittleness and ductility of shale are important evaluation parameters as they are closely related to natural shale fracture (Ding et al. 2012), artificial hydraulic fracturing (Ge et al. 2015), drilling (Eshkalak et al. 2015; Zeng et al. 2015), permeability (Ghanizadeh et al. 2013) and gas preservation (Yarali and Kahraman 2011; Gale et al. 2014; Hu et al. 2015; Liu and Sun 2015; Zeng et al. 2015). Brittleness is one of the most important mechanical parameters of unconventional gas shale reservoir 
estimation when it comes to hydraulic fracturing (Gasparrini et al. 2014; Holt et al. 2015) and borehole wall stability assessment and gas preservation risk (Ingram and Urai 1999; Hu et al. 2014; Zhou et al. 2014). Brittle shales are more likely to be naturally fractured and will also be more likely to respond well to hydraulic fracturing treatments (Nobakht et al. 2013). Natural fractures may provide some reservoir space for shale gas but also may result in shale gas leakage (Gale et al. 2014). Gas shale brittleness, a measure of the tendency of a rock to fracture, is a complex function of lithology, mineral composition, amount of total organic carbon (TOC), diagenesis, thermal maturity, porosity, effective stress, temperature and type of fluid in the pores (Wang and Gale 2009). The magnitude of shale brittleness is usually expressed by an index indicating how brittle a rock is, which has no unique definition. Different variations were employed as a brittleness index such as internal cohesion (Ramsey 1967), fracture with little or no plastic flow (Obert and Duvall 1967), stress-strain data (Kias et al. 2015), etc. In shale gas exploration and development, the brittle mineral content, the Young's modulus and Poisson's ratio are often employed to estimate shale brittleness. In terms of Poisson's ratio, the lower the value, the more brittle the shale, and as the value of Young's modulus increases, the more brittle the shale will be (Rickman et al. 2008). The quartz, feldspar and carbonate are the minerals recognized as brittle components of tight shale rocks (Chen and Xiao 2013). Quartz content can increase the brittleness and clay content will decrease the rock strength and brittleness of shale layers (Labani and Rezaee 2015). A rock with higher brittle mineral content also has higher brittleness (Liu and Sun 2015). Wang thought that brittle rocks generally comprise a high content of quartz and carbonates and the lowest clay content (Wang et al. 2015). However, shale brittleness is not totally intrinsic, but varies with environmental conditions. For example, high-level diagenetic shales with the same brittle mineral contents can be brittle, semi-brittle or even ductile under different confining pressures.

A parameter often used in soil mechanics to quantify the ductility or brittleness of clays is the over-consolidation ratio (OCR). It is defined as the ratio between the maximum effective vertical stress and the present effective vertical stress. Soil mechanics makes a clear distinction between materials that have been loaded previously to a higher effective stress level and then unloaded to its current in situ effective stress. These materials are called overconsolidated (OC) materials. If the current effective vertical stress in the material is as high or higher than at any time in its history, then the material is normally consolidated (NC). Over-consolidation in mudrocks and shales is caused by a combination of mechanical compaction and other non-mechanical factors leading to an apparent pre- consolidation. Shales which reach effective confining stresses above the apparent pre-consolidation stress are normally consolidated ( $\mathrm{NC}$ ), while those at effective confining stresses below apparent pre-consolidation are overconsolidated (OC). NC shales or those with low OCR show ductile behavior. OC shales with high OCR show brittle behavior (Nygård et al. 2006).

The brittle/ductile properties can mutually transform with burial depth in sedimentary basins. The most often used method of employing the brittle mineral contents to estimate the magnitude of shale brittleness in shale gas exploration field is not always suitable if burial depth is ignored. For example, even if the brittle mineral content of shale is very high (say as extremely high as $90 \%$ ), it cannot be considered that the shale rock has a high level of brittleness when it is in a deeply buried state. So, the burial depth must be taken into consideration when it comes to estimating the downhole shale brittleness. How to estimate the influence of the burial depth on shale brittleness is the main target of this paper.

In Southern China, there are several sets of shale with high levels of diagenesis, such as the Jurassic Tongzhuyuan, the Permian Longtan, the Silurian Longmaxi and the Cambrian Niutitang formations. Among them, the Longmaxi and Niutitang shales are the main marine sequences for shale gas exploration. These shales experienced early deep burial and late uplifting. The present-day burial depths were not the maximum burial depth they experienced in geological time. In this paper, we tried to set up a workflow of determining the depth interval of brittleness, semi-brittleness and ductility of such high-level diagenetic shales. The purpose is to roughly estimate shale gas preservation and hydraulic fracturing based on burial depth so as to lower geologic and engineering risks in exploration and production.

\section{A brief introduction of the workflow of determining BDTZ}

In our work flow, two boundaries were employed to mark the brittle/ductile properties of shale and they were determined by different methods (Fig. 1). The bottom boundary of the brittle zone (BZ) was determined with the threshold value of the over-consolidation ratio (OCR) of shale combined with the pre-consolidation stress. The top boundary of the ductile zone (DZ) is determined by a critical confining pressure. Hence the brittle-ductile transition zone (BDTZ) is limited between the two boundaries. 


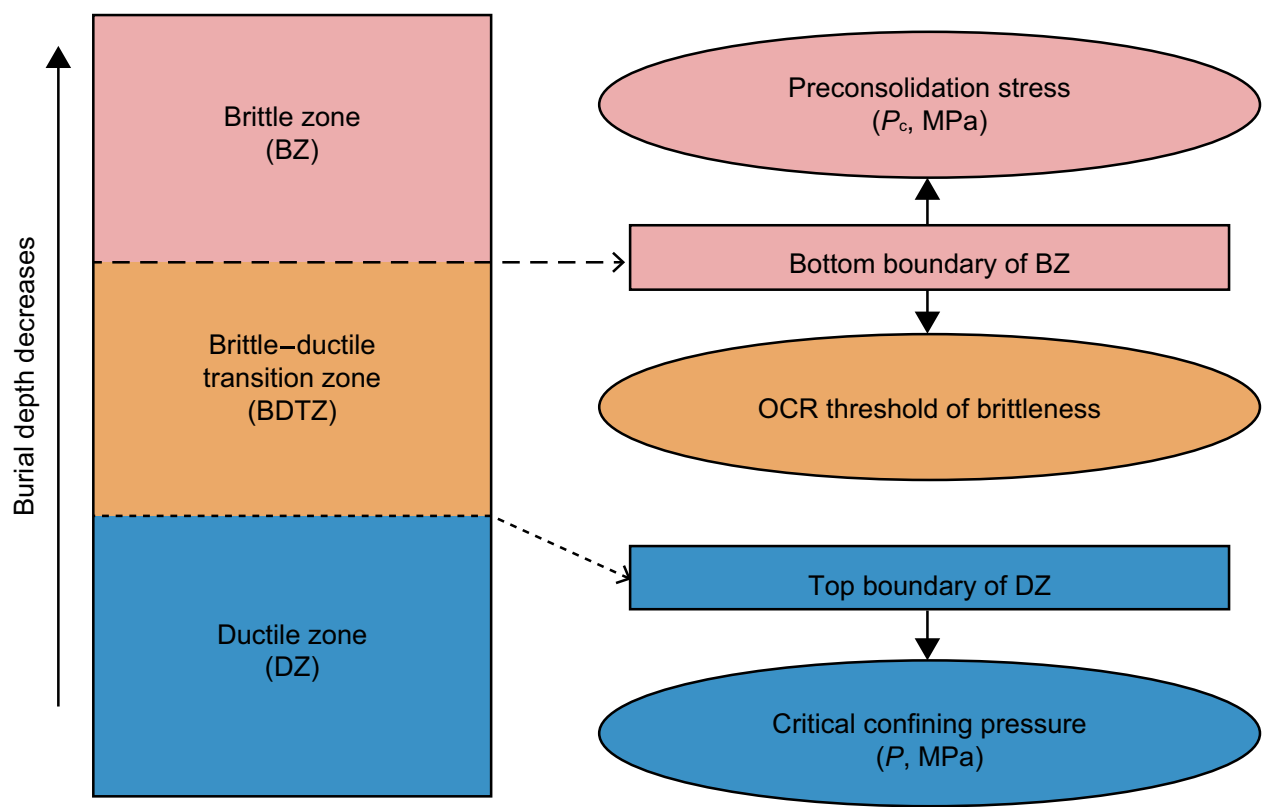

Fig. 1 Schematic diagram showing the workflow for determining the BDZT of shale

\section{Determination of the bottom boundary of the brittle zone}

Shale brittleness properties vary with confining pressure and therefore burial depth. Deeply buried shale under high confining pressure often shows ductile properties. The process from deep burial to shallow subsurface owing to tectonic uplift and/or erosion will result in a decrease of confining pressure and transformation of ductility to semibrittleness or even to brittleness. However, at what depth does a particular shale show ductility, semi-brittleness or brittleness? Firstly, the over-consolidation ratio (OCR) of shale was employed to determine the bottom boundary of the brittle zone (BZ), and the specific technical procedure is as follows:

1. Determination of pre-consolidation pressure $\left(p_{\mathrm{c}}\right)$ with a uniaxial strain test

2. Calculation of OCR under different confining pressures exerted in a triaxial compression test

3. Determination of the threshold value of OCR with a mathematical fitting

4. Reconstruction of maximum burial depth that the shale experienced in geological history and determination of the bottom boundary of BZ

\subsection{Determination of pre-consolidation pressure}

Pre-consolidation pressure refers to the maximum effective consolidation pressure experienced by the shale over its geological history. It is denoted by the symbol $p_{\mathrm{c}}$. The pre- consolidation pressure of soil can be obtained through a uniaxial compression test method. Similarly, the pre-consolidation pressure of shale rocks can be obtained through a uniaxial strain test according to the Passive Confining Pressure SHPB Test Method for Materials under QuasiOne Dimensional Strain State (Shi and Wang 2000). In our uniaxial strain test, we used a 10-mm-thick-wall cylinder made from 45\# steel with inside and outside radii of 23.5 and $33.5 \mathrm{~mm}$, respectively (Fig. 2). The axial stress is the stress vertically exerted on the shale sample in the experiment, and the lateral stress was calculated from:

$P=E \varepsilon\left(b^{2}-a^{2}\right) /\left(2 a^{2}\right)$

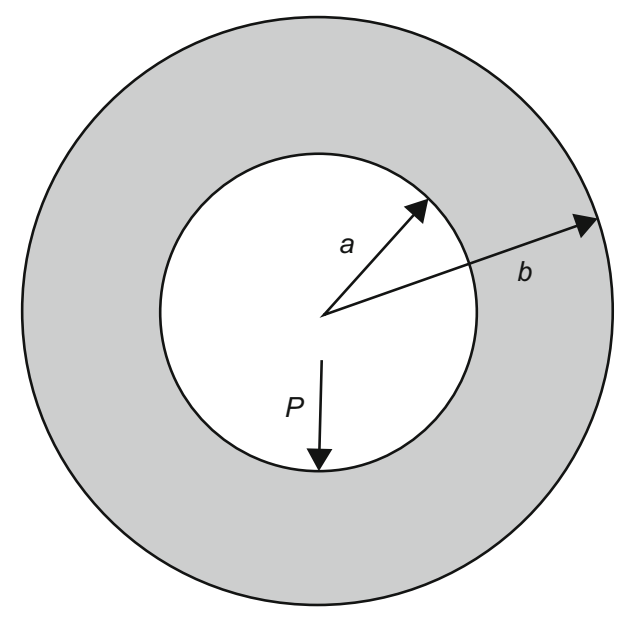

Fig. 2 Schematic diagram showing the size of the thick-wall cylinder and related parameters 
where $P$, lateral stress experienced by the inner wall, $\mathrm{MPa}$; $E$, Young's modulus of the steel, $2.06 \mathrm{E}+11 \mathrm{~Pa} ; \varepsilon$, lateral strain of the steel cylinder, $\% ; a$, inside radius of the steel cylinder, $23.5 \mathrm{~mm}$; $b$, outside radius of the steel cylinder, $33.5 \mathrm{~mm}$.

To compare the pre-consolidation pressure differences between shale rocks with different maximum burial depth and diagenesis, two types of shale samples were collected for the uniaxial strain test. One is the Silurian Longmaxi shale which experienced high level of diagenesis, and the other is the Jurassic Tongzhuyuan shale which experienced a relatively lower level of diagenesis. The two types of shale with different degrees of diagenesis have roughly the same mineral composition determined by X-ray diffraction analysis (XRD). The Silurian Longmaxi shale contains around $50 \%$ clay, $36 \%$ quartz, and $14 \%$ of other minerals including feldspar, dolomite, siderite, anhydrite, pyrite and pyroxene. The Jurassic Tongzhuyuan shale contains 50\% clay, $40 \%$ quartz and $10 \%$ other minerals. Two cylindrical samples were drilled from the same block of both types of shale rock. Based on the measured lateral strain of the steel cylinder, the lateral stress on the samples can be calculated from Eq. (1) and then the graph showing the relationship between the axial stress and the lateral stress can be constructed. The axial stress corresponding to the point signifying the variation of slope of the uniaxial strain test curve is the pre-consolidation pressure. According to Figs. 3 and 4, the pre-consolidation pressures of the Silurian Longmaxi shale and the Jurassic Tongzhuyuan shale are about 155 and $26 \mathrm{MPa}$, respectively (Table 1, Figs. 3, 4). The pre-consolidation pressure of the older, more deeply buried and highly diagenetic Silurian shale is much higher than that of the younger Jurassic shale.

\subsection{Over-consolidation ratio (OCR)}

In Southern China, sedimentary rocks experienced higher consolidation pressure (pre-consolidation pressure) in the geological history than that of present day. When a shale rock has been unloaded (e.g., due to uplift and erosion), the effective vertical stress supported by the shale at any time in the uplifting process should be less than the maximum effective vertical stress. The over-consolidation ratio at any time in the uplifting process is the ratio of maximum effective vertical stress $\left(\sigma_{v \max }^{\prime}\right)$ in the geological history to the effective vertical stress $\left(\sigma_{v(t)}^{\prime}\right)$ at the time of any burial depth in the uplifting process. Then, the over-consolidation ratio can be expressed by:

$\mathrm{OCR}=\sigma_{v \max }^{\prime} / \sigma_{v(t)}^{\prime}=P_{\mathrm{c}} / \sigma_{v(t)}^{\prime}$

where OCR, over-consolidation ratio; $\sigma_{v \max }^{\prime}$, maximum effective vertical stress, $\mathrm{MPa} ; \sigma_{v(t)}^{\prime}$, effective vertical stress at any time of uplifting process $P_{\mathrm{c}}$, pre-consolidation pressure, MPa.

According to Eq. (2), the OCR history can be reconstructed based on the burial history and erosion thickness reconstruction.

(b)

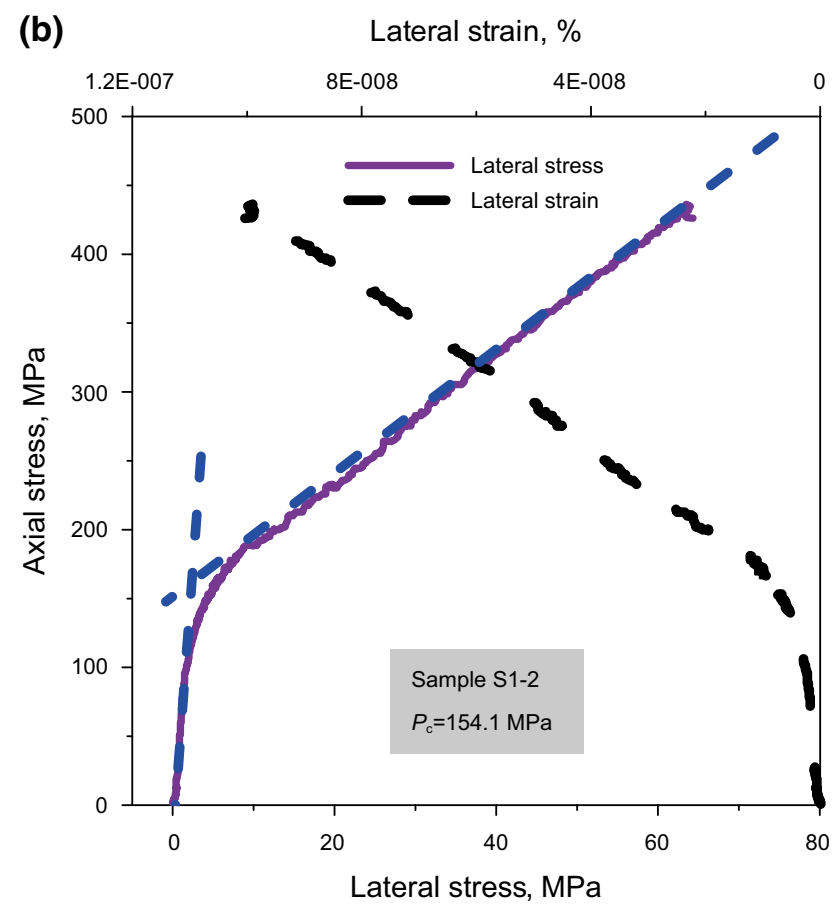

(a)

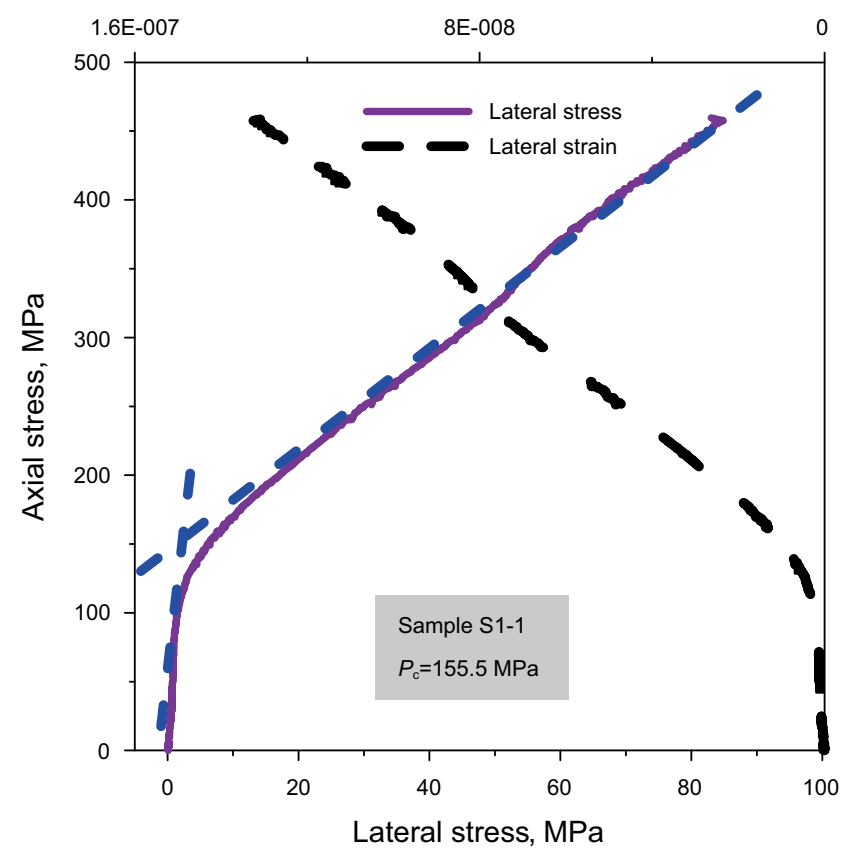

Lateral strain, \%

Fig. 3 Graph showing the determination of pre-consolidation pressure $\left(P_{\mathrm{c}}\right)$ of the Silurian shale 
(a)

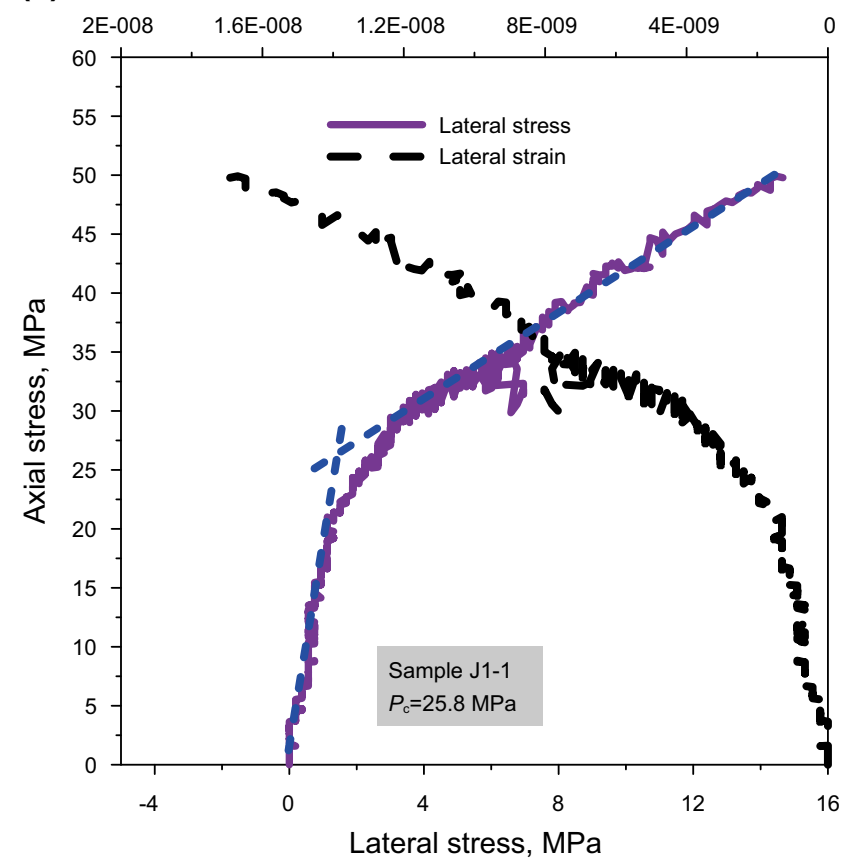

(b)

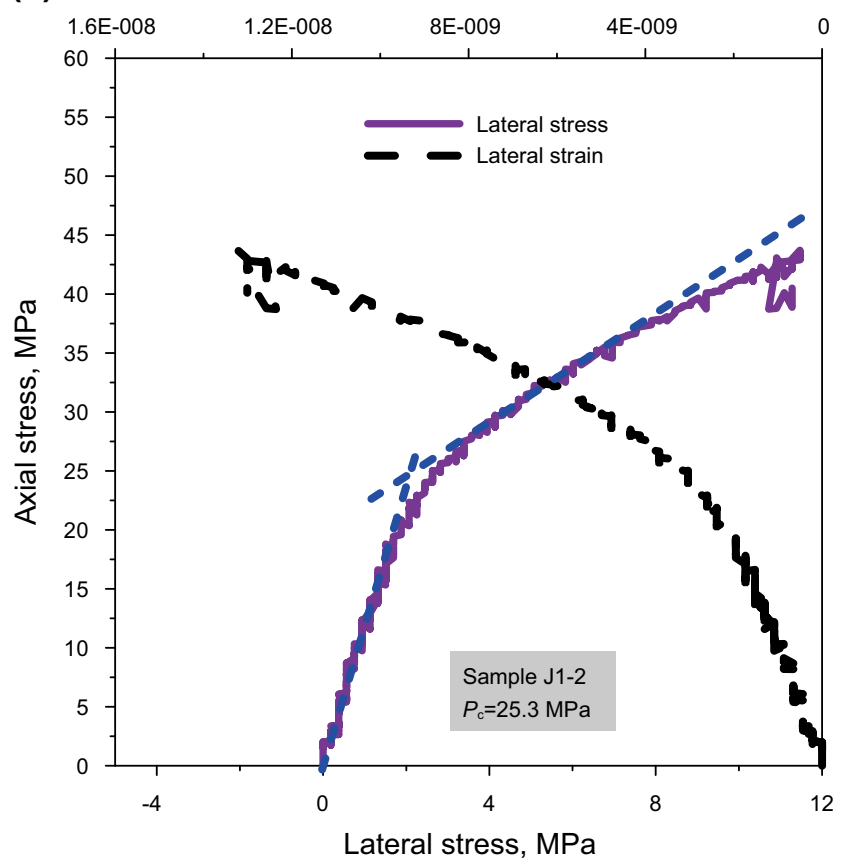

Fig. 4 Graph showing the determination of pre-consolidation pressure $\left(P_{\mathrm{c}}\right)$ of the Jurassic shale

Table 1 Basic information and measured pre-consolidation pressure of the samples

\begin{tabular}{|c|c|c|c|c|c|c|c|c|c|c|}
\hline \multirow[t]{2}{*}{ No. } & \multirow[t]{2}{*}{ Age } & \multirow[t]{2}{*}{ Formation } & \multirow[t]{2}{*}{ Height, mm } & \multirow[t]{2}{*}{ Diameter, $\mathrm{mm}$} & \multirow[t]{2}{*}{ Mass, $\mathrm{g}$} & \multirow[t]{2}{*}{ Density, $\mathrm{g} / \mathrm{cm}^{3}$} & \multirow[t]{2}{*}{$P_{\mathrm{c}}, \mathrm{MPa}$} & \multicolumn{3}{|c|}{ Mineral content, $\%$} \\
\hline & & & & & & & & Clay & Quartz & Others \\
\hline S1-1 & Silurian & Longmaxi & 99 & 46.94 & 455.36 & 2.66 & 155.5 & 50 & 36 & 14 \\
\hline S1-2 & Silurian & Longmaxi & 99.31 & 47.01 & 456.61 & 2.65 & 54.1 & & & \\
\hline $\mathrm{J} 1-1$ & Jurassic & Tongzhuyuan & 99.1 & 46.62 & 442.52 & 2.62 & 25.8 & 50 & 40 & 10 \\
\hline $\mathrm{J} 1-2$ & Jurassic & Tongzhuyuan & 99.52 & 46.91 & 446.47 & 2.60 & 25.3 & & & \\
\hline
\end{tabular}

In Sect. 3.1, a method of determining the pre-consolidation pressure has been introduced. In order to conveniently calculate the OCR, the confining pressure data in the triaxial compression test was taken as the effective vertical stress corresponding to the uplifting stage; therefore, the OCR values under different confining pressures can be calculated through Eq. (2).

Triaxial compression tests were conducted with an XTR01 microcomputer controlled electro-hydraulic servo triaxial tester jointly developed by Changchun Xinte Experimental Factory and Wuhan Institute of Rock and Soil Mechanics, Chinese Academy. Test samples were collected from Longmaxi shale in the same location of the Silurian Longmaxi samples for uniaxial strain test, and therefore it can be considered that they have the same mineral contents as shown in Table 1. The triaxial test results and calculated OCR values are shown in Table 2.
The peak stress is the axial stress when the shale samples failed under compression, confining pressure is the stress perpendicular to axial stress, and principal stress difference is the difference between peak stress and confining pressure. Normalized principal stress difference is the ratio of principal stress difference to confining pressure. The OCR values under different confining pressures are the ratio of pre-consolidation pressure to confining pressures. In Table 2, it can be seen that the OCR increases with decreasing confining pressure for a given pre-consolidation. It implies that the greater the uplifting erosion, the larger the OCR of the shale.

\subsection{Determination of the threshold value of OCR}

The over-consolidation ratio (OCR) can reflect the degree of brittleness of shale: the larger the OCR, the greater the 
Table 2 Triaxial compression test data and calculated OCR of samples collected from Longmaxi shale

\begin{tabular}{lllllr}
\hline Sample code & $\begin{array}{l}\text { Peak } \\
\text { stress } \\
\sigma_{1}, \mathrm{MPa}\end{array}$ & $\begin{array}{l}\text { Confining } \\
\text { pressure } \\
\sigma_{3}, \mathrm{MPa}\end{array}$ & $\begin{array}{l}\text { Principal stress } \\
\text { difference } \\
q_{u}=\sigma_{1}-\sigma_{3}, \mathrm{MPa}\end{array}$ & $\begin{array}{l}\text { Normalized principal } \\
\text { stress difference } \\
q_{u} / \sigma_{3}, \mathrm{MPa}\end{array}$ & $\begin{array}{l}\text { Pre-consolidation } \\
\text { pressure } \\
P_{\mathrm{c}}, \mathrm{MPa}\end{array}$ \\
\hline 1 & 59.42 & 1.93 & 57.49 & 29.78 & 155 \\
2 & 76.27 & 7.69 & 68.58 & 8.92 & 20.2 \\
3 & 82.36 & 7.69 & 74.67 & 9.71 & 20.2 \\
4 & 112.13 & 15.49 & 96.65 & 6.24 & 10.0 \\
5 & 149.09 & 30.98 & 118.11 & 3.81 & 5.0 \\
6 & 173.87 & 45.99 & 127.88 & 2.78 & 3.4 \\
\hline
\end{tabular}

brittleness (Nygård et al. 2006; Stróżyk and Tankiewicz 2014). OCR of normally consolidated shale (NC shale) is 1 , and OCR of over-consolidated shale (OC shale) is more than 1 . The key issue is that, with what OCR value the shale will become completely brittle? We define the OCR value of the shale rock transformed from semi-brittle to completely brittle as a threshold of OCR of brittle shale $\left(\mathrm{OCR}_{\text {threshold }}\right)$.

OCR can reflect not only the brittleness of shale, but also the shearing strength (Nygård et al. 2006). The relationship between OCR and normalized shearing strength $\left(q_{u} / \sigma_{3}\right)$ can be established from the analysis of triaxial compression test results obtained from stress history and the normalized soil engineering method (SHANSEP method) (Ladd and Foott 1974):

$q_{u} / \sigma_{3}=a(\mathrm{OCR})^{b}$

where $q_{u}$ is principal stress difference in the triaxial test, $\sigma_{3}$ is confining pressure in the triaxial test, OCR is the overconsolidation ratio of shale, $a$ (empirical coefficient) is the equal of normalized shearing strength of normally consolidated shale $(\mathrm{OCR}=1)$, and $b$ is a fitting parameter. As can be seen, the larger the OCR, the greater the normalized shearing strength of the shale is.

If the OCR is associated with BRI (Ingram and Urai 1999), then:

$\frac{\left(q_{u} / \sigma_{3}\right)_{\mathrm{OC}}}{\left(q_{u} / \sigma_{3}\right)_{\mathrm{NC}}} \approx \frac{\left(\sigma_{c}\right)_{\mathrm{OC}}}{\left(\sigma_{c}\right)_{\mathrm{NC}}}=\mathrm{BRI}=(\mathrm{OCR})^{b}$

When BRI is more than 2, shale is completely brittle, and the larger the BRI, the greater the brittleness (Ingram and Urai 1999). Therefore, the OCR value when $\mathrm{OCR}^{b}=2$ can be set as the threshold value of brittleness of shale, of which $b$ is obtained from fitting of normalized shear stress and OCR data.

For example, the over-consolidation ratio and threshold value of shale have been determined for the Longmaxi shale in eastern Sichuan. A crossplot was drawn with normalized principal stress difference and OCR data in Table 2. The function relationship between normalized principal stress difference and OCR was obtained with data fitting. It is $q_{u} / \sigma_{3}=2.4723(\mathrm{OCR})^{0.7285}$ with $R^{2}=0.9927$, indicating very high fitting degree (Fig. 5). As can be seen, the empirical coefficient $b$ is 0.7285 and $\mathrm{OCR}^{b}=2$. The calculated threshold value of $\mathrm{OCR}\left(\mathrm{OCR}_{\text {threshold }}\right)$ is 2.6. When the OCR reaches 2.6, the Longmaxi shale will become completely brittle.

\subsection{Bottom boundary of the brittle zone (BZ)}

The bottom boundary of the brittle zone can be consequently calculated with the definition of OCR (the ratio of maximum vertical effective stress to present vertical effective stress) after obtaining the threshold value of OCR.

The average formation water density of the overlying strata of the Longmaxi Formation is about 1.07. From the definition of the OCR:

$\mathrm{OCR}=\frac{\sigma_{v \max }^{\prime}}{\sigma_{v}^{\prime}} \approx \frac{\left(\rho_{1}-1.07\right) H_{\max }}{\left(\rho_{2}-1.07\right) H_{\text {present }}}$

where $\sigma_{v \max }^{\prime}$, maximum effective vertical stress, MPa; $\sigma_{v}^{\prime}$, current effective vertical stress, $\mathrm{MPa} ; \rho_{1}$, the average density of overlying strata at the maximum burial depth, $g$ / $\mathrm{cm}^{3} ; \rho_{2}$, the average density of current overlying strata, $\mathrm{g} /$

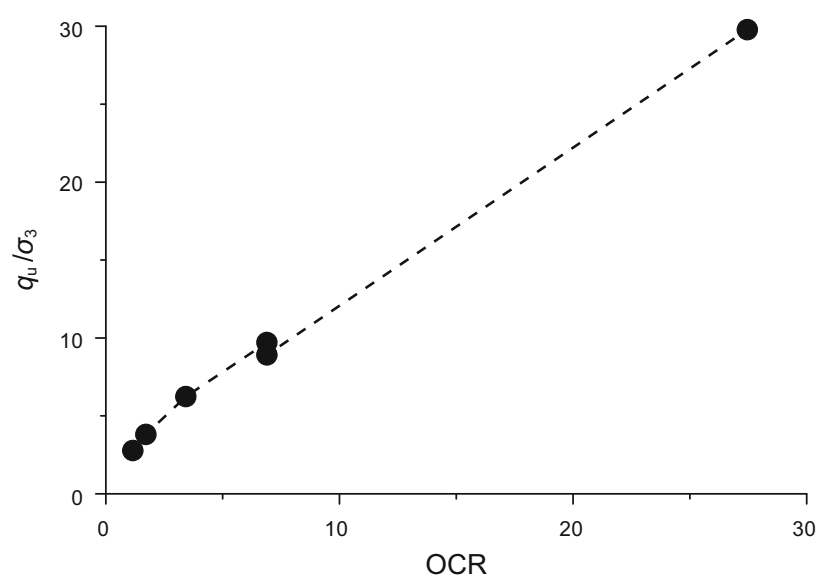

Fig. 5 Crossplot of normalized principal stress difference and OCR of shale in Silurian in eastern Sichuan and western Hubei area 
$\mathrm{cm}^{3} ; H_{\max }$, maximum burial depth, $\mathrm{m} ; H_{\text {present }}$, current burial depth, $\mathrm{m}$.

The burial depth is the bottom boundary $\left(H_{\mathrm{b}}\right)$ of brittle zone when OCR reached the threshold value and is determined by:

$H_{\mathrm{b}} \approx \frac{H_{\max }}{\mathrm{OCR}_{\text {threshold }}}$

The maximum burial depth of the bottom boundary of the Silurian $\left(H_{\max }\right)$ was obtained from burial history reconstruction. It omitted the descriptions about how to reconstruct the burial history of the Silurian shale based on the back-stripping method (Springer 1993) in consideration of the paper page limits. The bottom boundary of the brittle zone can be calculated with Eq. (6). Using the threshold value of Longmaxi shale of 2.6 as calculated in the previous section, five shale gas exploration wells have been examined and the results are shown in Table 3. As can be seen, the bottom boundary of BZ of the Silurian shale varies with its maximum burial depth. The deeper the maximum burial depth, the deeper the bottom boundary of $\mathrm{BZ}$ of a given shale located.

\section{Determination of top boundary of ductile zone (DZ)}

The brittle-ductile transition controlled by confining pressure is not sudden, but a gradual transition. There is a transitional zone of ductile brittleness and brittle ductility between completely brittle and completely ductile. Generally, the confining pressure value of the post-peak of stress-strain curve shown as perfect plasticity is defined as the critical confining pressure of the brittle-ductile transition (Mogi 1965).

It is relatively easy to determine the top boundary of the ductile zone. The critical confining pressure of the brittleductile transition only needs to be converted into depth. The ratio of residual strength to peak strength can be calculated with the triaxial compression test data, and it can be applied to compile a crossplot of confining pressure and the ratio of residual strength to peak strength (Fig. 6). The mathematical model between the confining pressure and residual/peak strength of different types of shale can be obtained through linear fitting. When residual strength/peak strength is 1 , the confining pressure is the critical confining pressure of the brittle-ductile transition of shale and the converted depth $\left(H_{\mathrm{d}}\right)$ is the top boundary of the ductile zone.

As shown in Fig. 6, the ratio of the residual and peak strength increases with increasing confining pressure. There is a good linear relationship between them, which is $y=a x-b$. Then, when $x=1, y=a-b$, and it is the critical confining pressure of the brittle-ductile transition. From the fitting relation $y=112.66 x-41.415$ from Fig. 6 , the critical confining pressure of brittle-ductile transition of the Longmaxi shale is $71.2 \mathrm{MPa}$. Given the density $(\rho)$ of overlying strata, the critical depth of the brittle-ductile transition can be calculated, namely the depth of the top boundary of the ductile zone $\left(H_{\mathrm{d}}\right)$ :

$H_{\mathrm{d}}=100 \times(a-b) /(\rho-1.07)$

The average density of overlying strata of the Longmaxi shale in eastern Sichuan-western Hubei area calculated from log curve (Fig. 7) is $2.67 \pm 0.065 \mathrm{~g} / \mathrm{cm}^{3}$, and the calculated top boundary depth $\left(H_{\mathrm{d}}\right)$ of the ductile zone is about $4470 \pm 230 \mathrm{~m}$ (Table 4 ). In other words, in eastern Sichuan-western Hubei area, the Longmaxi shale will be ductile when its present burial depth is deeper than $4470 \pm 230 \mathrm{~m}$.

\section{Brittle-ductile transitional zone (BDTZ) and discussions}

After determining the bottom boundary of BZ and top boundary of DZ, the BDTZ (Brittle-ductile transitional zone), BZ (brittle zone) and DZ (ductile zone) are all determined. The bottom boundary of $\mathrm{BZ}$ varies with the maximum burial depth. The TBDZ varies due to differences of the average density of overlying strata except for the critical confining pressure; thus, the BDTZ of shale is

Table 3 Calculation of bottom boundary of brittle zone of shale in Silurian eastern Sichuan and western Hubei area

\begin{tabular}{llll}
\hline Well name & $\begin{array}{l}\text { Maximum depth of } \\
\text { Silurian bottom } \\
H_{\max }, \mathrm{m}\end{array}$ & $\begin{array}{l}\text { Current depth of } \\
\text { Silurian bottom } \\
H_{\text {present }}, \mathrm{m}\end{array}$ & $\begin{array}{l}\text { Bottom } \\
\text { boundary of BZ } \\
H_{\mathrm{b}}, \mathrm{m}\end{array}$ \\
\hline Jiaoye1 & 5708 & 2409 & 2195 \\
Heye1 & 6461 & 2162 & 2485 \\
Jianshen1 & 7184 & 4986 & 2763 \\
Dingye1HF & 5045 & 2050 & 1940 \\
Dingye2HF & 6354 & 4359 & 2443 \\
\hline
\end{tabular}




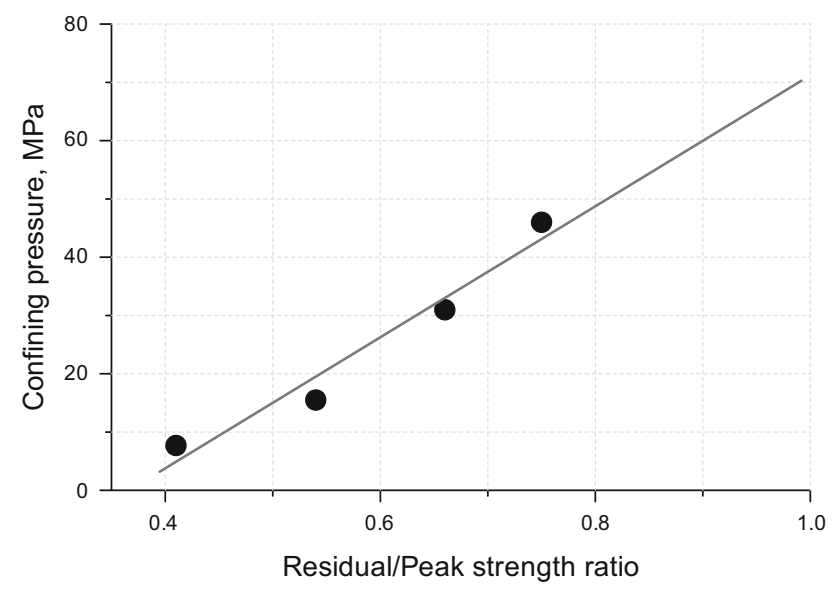

Fig. 6 Variation of residual strength/peak intensity of Longmaxi shale with the confining pressure

accordingly different in different areas. For example, the TBDZ of Longmaxi shale of wells Jiaoye1, Heye1 and Jianshen 1 is 4464,4428 and $4545 \mathrm{~m}$, respectively, and the bottom boundary of BZ is 2195, 2485 and $2763 \mathrm{~m}$, respectively. Then, the BDTZ is $2195-4464,2485-4428$ and 2763-4545 m, respectively. The current brittle/ductile characteristics of shale can be determined as the present burial depth is known. As can been seen from Tables 3 and 4, the Longmaxi shale of well Jiaoye1, well Heye1 and well Jianshen1 is in BDTZ, BZ and DZ, respectively (Fig. 8).

The BDTZ may be the best depth interval for shale gas exploration in highly mature marine shales in South China which experienced multistages of tectonic movement and extensive uplifting and erosion. Brittle/ductile characteristics of shale are closely related to natural fractures, thus controlling the gas preservation and affecting the reservoir properties and compressibility (hydraulic response). Although shale in the brittle zone is characterized by "good" brittleness and compressibility, extensional fractures may occur under tectonic stress during uplift and erosion; thus, preservation conditions may have been destroyed, resulting in great loss of free gas in the shale. Although shale in the ductile zone is characterized by "good" ductility and "good" sealing capacity which is not prone to develop brittle fracture under tectonic stress, the compressibility is poor and hydraulic fractures are prone to be closed under high confining pressure. In contrast, shale in the BDTZ is characterized by semi-brittle properties with some extent of compressibility and disconnected micro-fractures which may not destroy the preservation conditions of shale gas; therefore, it is the most beneficial condition for development of reservoir space and shale gas preservation, as the most favorable depth interval for shale gas exploration as well as development.
Existing exploration and development wells in highly mature marine shales in Southern China have verified that the BDTZ is a "golden zone" for shale gas exploration. The burial depth of the Silurian Longmaxi shale with high and stable gas production is mostly distributed in the BDTZ. When the Longmaxi shale is located in the brittle zone, the bore hole often does not have commercial productivity and shale gas components are mainly adsorbed gas with very low free gas content. When the Longmaxi shale is located in the ductile zone, the productivity is difficult to maintain stable despite it possibly having high initial production.

The Longmaxi Formation in the Jiaoshiba area of Southern China is distributed in the BTDZ, where a giant shale gas field has been found. The depth of drilling horizontal section in four exploration wells in Jiaoshiba structure ranges from $2385-2415 \mathrm{~m}$ and tested $110-500$ thousand cubic meters of natural gas per day in these wells. For example, well Jiaoye1 tested initial gas production of 203,000 cubic meters a day and keeps more than 60,000 cubic meters per day after 2 years of production test. The pressure and gas yield remain stable, with a formation pressure coefficient of 1.55 (Guo and Zhang 2014). The content of free gas in the shale gas in well Jiaoye1 is more than 50\%. The Longmaxi shale of well Heye1, which located in western Hubei, is in the brittle zone. No gas flows were obtained after hydraulic fracturing, and only sporadic bubbles were seen on the surface of shale cores in the water treatment test. Formation pressure is normal and the pressure coefficient is about 1.0. Gas content tested at 2156.22 and $2163.87 \mathrm{~m}$ of well Heye1 showed that the total gas content was 0.74 and $0.86 \mathrm{~m}^{3} / \mathrm{t}$, respectively, and dominated by adsorbed gas.

For well Dingye2HF in Southeastern Sichuan Basin, the Longmaxi Formation is located in the ductile zone. The highest initial production was up to $100,000 \mathrm{~m}^{3} /$ day, but soon fell to $26,000 \mathrm{~m}^{3} /$ day. Great differences of shale gas production, stable production period, contents of adsorbed or free gas between the above wells which are located in different zones may not result from factors such as source rock, reservoir condition, geologic element of hydrocarbon accumulation, but mainly from preservation or hydraulic fracturing capacity controlled by shale brittleness/ductility. TOC content and thermal maturity of well Heye1 are roughly the same as those of well Jiaoye1. The TOC of the Longmaxi Formation in well Heye1 ranges from $1.28 \%$ to $5.28 \%$ with an average of $2.54 \% ; R_{\mathrm{O}}$ is between $2.6 \%$ and $2.8 \%$ with a median of $2.7 \%$. TOC of the Longmaxi Formation in well Jiaoye1 is in the range of $0.8 \%-5.8 \%$ averaging at $2.5 \% ; R_{\mathrm{o}}$ ranges from $2.5 \%$ to $3.1 \%$. However, the former well has no productivity and the latter is an industrial shale gas well with high productivity. The main reason is that Longmaxi shale in well Heye 1 is located in 

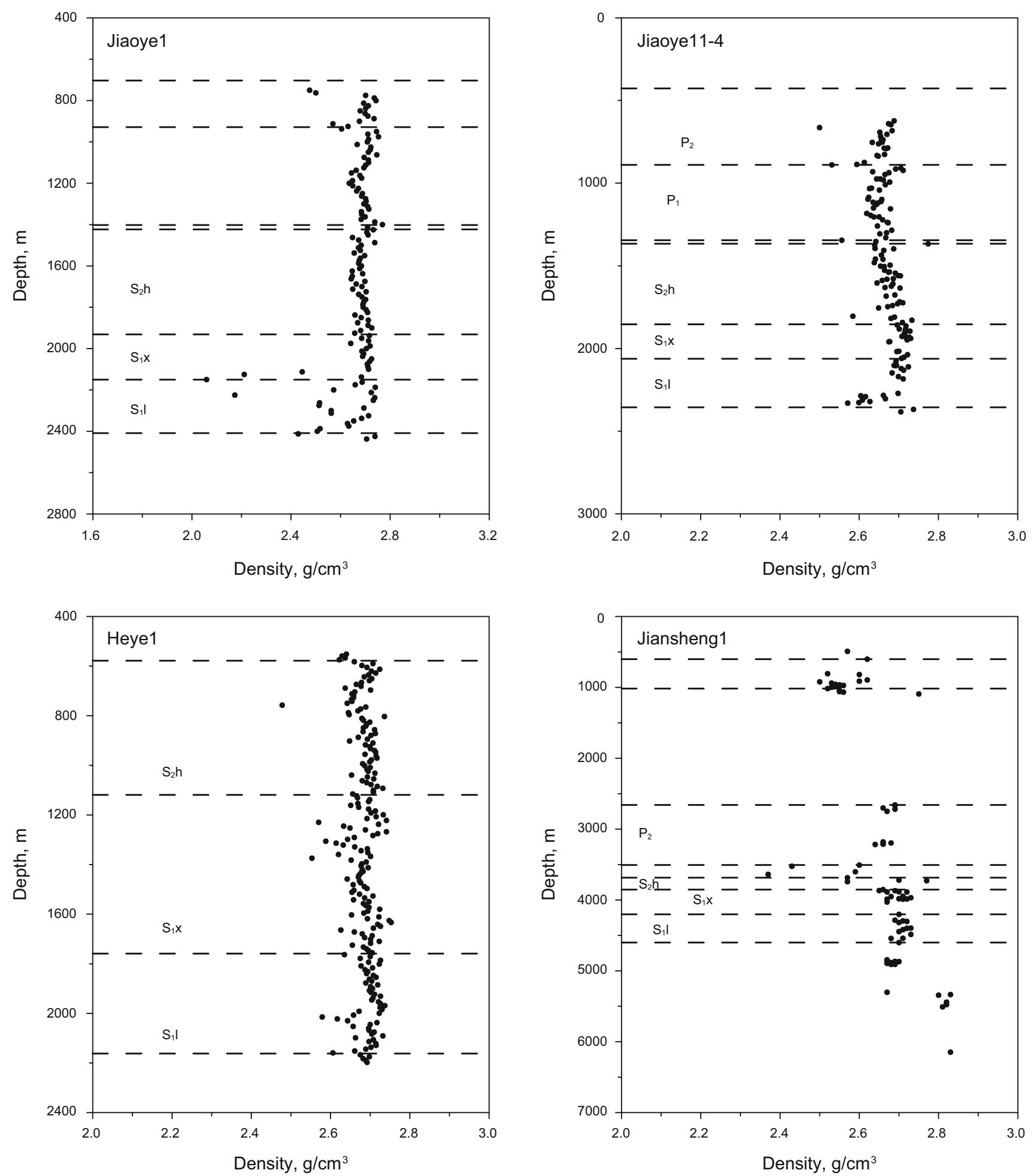

Fig. 7 Density log curves of overlying strata of Longmaxi shale in the representative shale gas exploration wells in South China

the brittle zone, where preservation was destroyed. The latter is in the BDTZ, the "golden zone" of shale gas exploration. Moreover, the Longmaxi shale in well Heye1 is characterized by low gas content and mainly adsorbed gas, indicating great loss of free gas resulting from poor preservation in the brittle zone in complicated structure areas. Additionally, the Longmaxi Formation pressure coefficient is 1.0 in well Heye1, while it is 1.45 in well Jianye1. It also shows the difference of preservation between the BZ and BDTZ. The former is poor and the 
Table 4 Calculated TBDZ of the Silurian Longmaxi shale in eastern Sichuan and western Hubei area

\begin{tabular}{|c|c|c|c|c|}
\hline Well name & $\begin{array}{l}\text { Average density of } \\
\text { overlying strata, } \mathrm{g} / \mathrm{cm}^{3}\end{array}$ & $\begin{array}{l}\text { Standard deviation of } \\
\text { density, } \mathrm{g} / \mathrm{cm}^{3}\end{array}$ & $\begin{array}{l}\text { Top boundary of } \\
\text { ductile zone }\left(H_{\mathrm{d}}\right), \mathrm{m}\end{array}$ & $\begin{array}{l}\text { Standard deviation } \\
\text { of } H_{\mathrm{d}}, \mathrm{m}\end{array}$ \\
\hline Jiaoye1 & 2.67 & 0.078 & 4464 & 319 \\
\hline Jiaoye 11-4 & 2.67 & 0.038 & 4466 & 109 \\
\hline Heye 1 & 2.68 & 0.049 & 4428 & 184 \\
\hline Jianshen 1 & 2.64 & 0.082 & 4545 & 252 \\
\hline Dingye1HF & 2.67 & 0.098 & 4492 & 411 \\
\hline Dingye2HF & 2.68 & 0.043 & 4438 & 132 \\
\hline Ensemble average & 2.67 & 0.0646 & 4470 & 230 \\
\hline
\end{tabular}

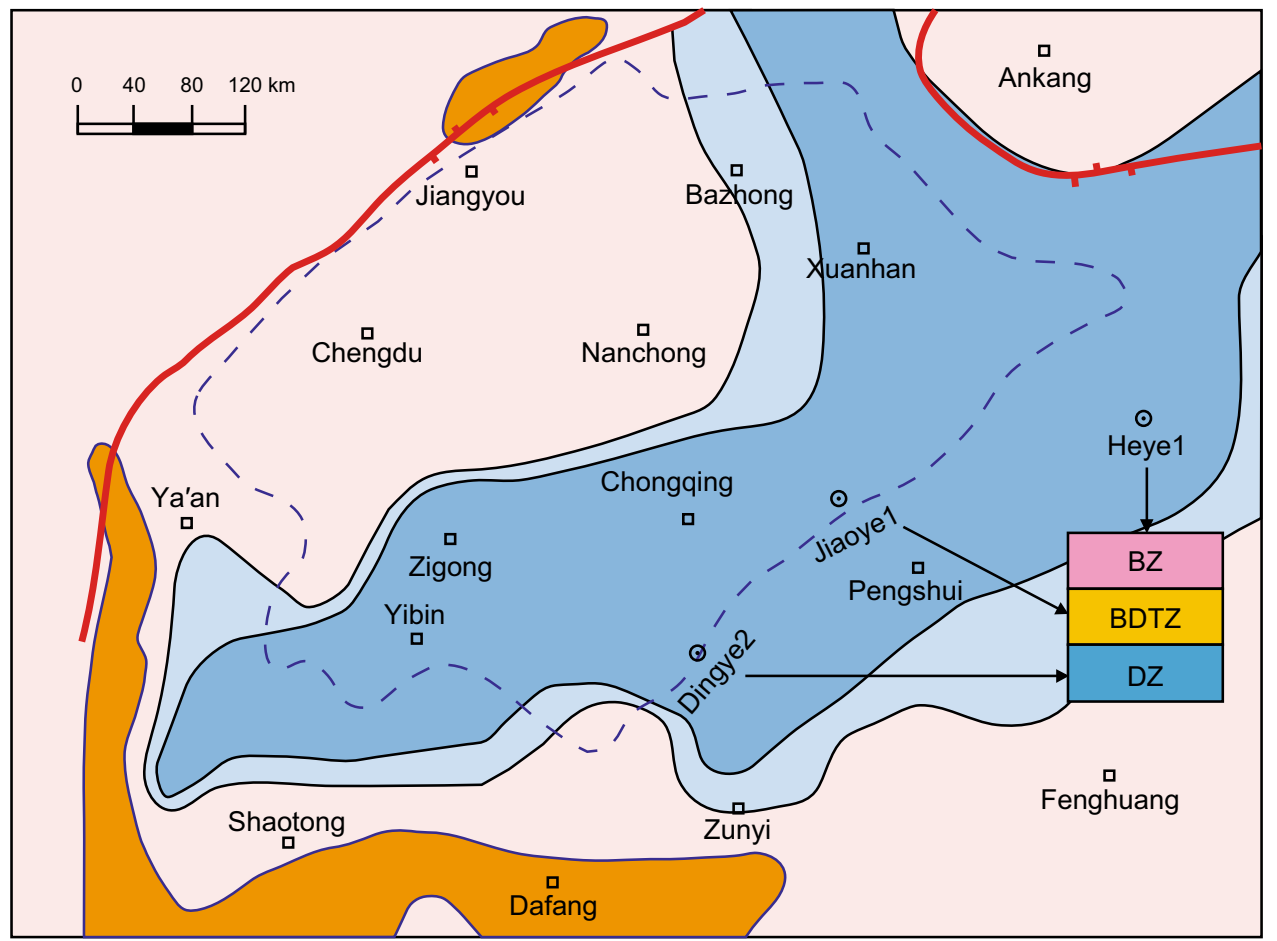

Fig. 8 Locations of the shale gas exploration wells involved in the discussion

latter is good. On the contrary, the Longmaxi shale in well Dingye2HF lies in the ductile zone. Although the preservation condition is good and the initial production is high, the shale is in ductile state and hydraulic fractures are prone to become closed under high confining pressure, resulting in rapid decrease of yields.

\section{Conclusions}

Shale brittleness and ductility are key parameters for estimation of shale gas preservation and hydraulic fracturing. Both maximum and current burial depth significantly affect shale brittleness. We established a work flow for determining the depth interval of shale brittleness and ductility.
1) The bottom boundary of BZ of shale can be determined based on the maximum burial depth and the threshold value of OCR. The top boundary of the ductile zone (DZ) can be determined based on the critical confining pressure of brittle-ductile transition.

2) The top boundary of DZ of the Silurian Longmaxi shale in eastern Sichuan-western Hubei areas is about $4470 \pm 230 \mathrm{~m}$. The bottom boundary of BZ varies with maximum burial depth. The greater the maximum burial depth, the deeper the bottom boundary of BZ.

3) The brittle-ductile transitional zone (BDTZ) is normally "the best depth interval" for shale gas exploration in Southern China. The preservation conditions may be destroyed in the BZ because of brittle fracturing. The DZ does not response well to 
hydraulic fracturing treatment because of fracture self-sealing. The BDTZ not only developed some natural micro-fractures, but also is characterized by good compressibility which responds well to hydraulic fracturing. It is favorable for shale gas accumulation and preservation. The BDTZ is the most favorable depth zone for shale gas exploration and development. The BDTZ determined by our workflow can be used as a main parameter of geological and engineering risk assessment for Paleozoic marine shale gas in Southern China.

Acknowledgements This paper was financially supported by the National Science \& Technology Special Project (Grant No. 2016ZX05061001). We appreciate Prof. Lloyd Snowdon for his careful corrections of English style and grammar and useful comments and suggestions.

Open Access This article is distributed under the terms of the Creative Commons Attribution 4.0 International License (http://creative commons.org/licenses/by/4.0/), which permits unrestricted use, distribution, and reproduction in any medium, provided you give appropriate credit to the original author(s) and the source, provide a link to the Creative Commons license, and indicate if changes were made.

\section{References}

Chen J, Xiao X. Mineral composition and brittleness of three sets of Paleozoic organic-rich shales in China South area. J China Coal Soc. 2013;38(5):822-6. doi:10.13225/j.cnki.jccs.2013.05.018 (in chinese).

Dewhurst DN, Sarout J, Delle Piane C, et al. Empirical strength prediction for preserved shales. Mar Pet Geol. 2015;67:512-25. doi:10.1016/j.marpetgeo.2015.06.004.

Ding W, Li C, Li C, et al. Fracture development in shale and its relationship to gas accumulation. Geosci Front. 2012;3(1):97-105. doi:10.1016/j.gsf.2011.10.001.

Eshkalak MO, Aybar U, Sepehrnoori K. On the feasibility of restimulation of shale wells. Pet Sci. 2015;12(3):553-9. doi:10. 1007/s12182-015-0036-7.

Gale JFW, Laubach SE, Olson JE, et al. Natural fractures in shale: a review and new observations. AAPG Bull. 2014;98(11):2165-216. doi:10.1306/08121413151.

Gasparrini M, Sassi W, Gale JFW. Natural sealed fractures in mudrocks: a case study tied to burial history from the Barnett Shale, Fort Worth Basin, Texas, USA. Mar Pet Geol. 2014;55:122-41. doi:10.1016/j.marpetgeo.2013.12.006.

Ge H, Yang L, Shen Y, et al. Experimental investigation of shale imbibition capacity and the factors influencing loss of hydraulic fracturing fluids. Pet Sci. 2015;12(4):636-50. doi:10.1007/ s12182-015-0049-2.

Ghanizadeh A, Gasparik M, Amann-Hildenbrand A, et al. Lithological controls on matrix permeability of organic-rich shales: an experimental study. Energy Procedia. 2013;40:127-36. doi:10. 1016/j.egypro.2013.08.016.

Guo T, Zhang H. Formation and enrichment mode of Jiaoshiba shale gas field, Sichuan Basin. Pet Explor Dev. 2014;41(1):31-40. doi:10.1016/S1876-3804(14)60003-3.

Holt RM, Fjær E, Stenebråten JF, et al. Brittleness of shales: relevance to borehole collapse and hydraulic fracturing. J Pet Sci Eng. 2015;131:200-9. doi:10.1016/j.petrol.2015.04.006.
Hu D, Zhang H, Ni K, et al. Preservation conditions for marine shale gas at the southeastern margin of the Sichuan Basin and their controlling factors. Nat Gas Ind B. 2014;1(2):178-84. doi:10. 1016/j.ngib.2014.11.009.

$\mathrm{Hu}$ Q, Liu X, Gao Z, et al. Pore structure and tracer migration behavior of typical American and Chinese shales. Pet Sci. 2015;12(4):651-63. doi:10.1007/s12182-015-0051-8.

Ingram GM, Urai JL. Top-seal leakage through faults and fractures: the role of mudrock properties. Geol Soc Lond Spec Publ. 1999;158(1):125-35.

Kias E, Maharidge R, Hurt R. Mechanical versus mineralogical brittleness indices across various shale plays. In: SPE annual technical conference and exhibition held in Houston, Texas, USA, 28-30 Sept 2015, SPE-174781-MS; 2015.

Labani MM, Rezaee R. The importance of geochemical parameters and shale composition on rock mechanical properties of gas shale reservoirs: a case study from the Kockatea Shale and Carynginia Formation from the Perth Basin, Western Australia. Rock Mech Rock Eng. 2015;48(3):1249-57. doi:10.1007/ s00603-014-0617-6.

Ladd CC, Foott R. New design procedure for stability of soft clays. J Geotech Eng Div. 1974;100(GT7):763-86.

Liu Z, Sun Z. New brittleness indexes and their application in shale/clay gas reservoir prediction. Pet Explor Dev. 2015;42(1):129-37. doi:10.1016/S1876-3804(15)60016-7.

Mogi K. Deformation and fracture of rocks under confining pressure elasticity and plasticity of some rocks. Bull Earthq Res Inst Tokyo Univ. 1965;43:349-79.

Nobakht M, Clarkson CR, Kaviani D. New type curves for analyzing horizontal well with multiple fractures in shale gas reservoirs. J Nat Gas Sci Eng. 2013;10:99-112. doi:10.1016/j.jngse.2012.09.002.

Nygård R, Gutierrez M, Bratli RK, et al. Brittle-ductile transition, shear failure and leakage in shales and mudrocks. Mar Pet Geol. 2006;23(2):201-12. doi:10.1016/j.marpetgeo.2005.10.001.

Obert L, Duvall WI. Rock mechanics and the design of fractures in rock. New York: Wiley; 1967. p. 278.

Ramsey JG. Folding and fracturing of rocks. London: McGraw-Hill; 1967. p. 289.

Rickman R, Mullen M, Petre E, et al. A practical use of shale petrophysics for stimulation design optimization: all shale plays are not clones of the Barnett Shale. In: SPE annual technical conference and exhibition, society of petroleum engineers; 2008. p. 21-4.

Shi S, Wang L. Passive confined pressure SHPB test method for materials under quasi-one dimensional strain state. J Exp Mech. 2000;15(4):377-84 (in chinese).

Springer J. Decompaction and backstripping with regard to erosion, salt movement, and interlayered bedding. Comput Geosci UK. 1993;19(8):1115-25.

Stróżyk J, Tankiewicz M. The undrained shear strength of overconsolidated clays. Procedia Eng. 2014;91:317-21. doi:10.1016/j. proeng.2014.12.067.

Wang FP, Gale JF. Screening criteria for shale-gas systems. Gulf Coast Assoc Geol Soc Trans. 2009;59:779-93.

Wang D, Ge H, Wang X, et al. A novel experimental approach for fracability evaluation in tight-gas reservoirs. J Nat Gas Sci Eng. 2015;23:239-49. doi:10.1016/j.jngse.2015.01.039.

Yarali O, Kahraman S. The drillability assessment of rocks using the different brittleness values. Tunn Undergr Space Technol. 2011;26(2):406-14. doi:10.1016/j.tust.2010.11.013.

Zeng Y, Zhang X, Zhang B. Stress redistribution in multi-stage hydraulic fracturing of horizontal wells in shales. Pet Sci. 2015;12(4):628-35. doi:10.1007/s12182-015-0048-3.

Zhou Q, Xiao X, Tian H, et al. Modeling free gas content of the Lower Paleozoic shales in the Weiyuan area of the Sichuan Basin, China. Mar Pet Geol. 2014;56:87-96. doi:10.1016/j. marpetgeo.2014.04.001. 